THEODORI SCUTARIOTAE CHRONICA 


\section{CORPUS FONTIUM \\ HISTORIAE BYZANTINAE}

CONSILIO SOCIETATIS INTERNATIONALIS STUDIIS BYZANTINIS PROVEHENDIS DESTINATAE EDITUM

VOLUMEN XLVI

SERIES BEROLINENSIS

EDIDIT

ATHANASIOS KAMBYLIS

DE GRUYTER

BEROLINI ET BOSTONIAE MMXV 


\title{
THEODORI SCUTARIOTAE CHRONICA
}

\author{
EDITIO PRINCEPS
}

RECENSUIT ET INDICIBUS INSTRUXIT

RAIMONDO TOCCI

DE GRUYTER

BEROLINI ET BOSTONIAE

MMXV 
ISBN 978-3-11-018946-9

e-ISBN (PDF) 978-3-11-021692-9

e-ISBN (EPUB) 978-3-11-038431-4

ISSN 0077-7688

Library of Congress Cataloging-in-Publication Data

A CIP catalog record for this book has been applied for at the Library of Congress.

Bibliografische Information der Deutschen Nationalbibliothek.

Die Deutsche Nationalbibliothek verzeichnet diese Publikation in der Deutschen Nationalbibliografie; detaillierte bibliografische Daten sind im Internet über http://dnb.dnb.de abrufbar.

(C) 2015 Walter de Gruyter GmbH, Berlin/Boston

Druck und Bindung: Hubert \& Co. GmbH \& Co. KG, Göttingen

$\infty$ Gedruckt auf säurefreiem Papier

Printed in Germany

www.degruyter.com 